\title{
Awareness of osteoporosis and its relationship with calcaneus quantitative ultrasound in a large Chinese community population
}

This article was published in the following Dove Press journal:

Clinical Interventions in Aging

26 June 2013

Number of times this article has been viewed

\author{
Jingjing $\mathrm{Xu}^{1, *}$ \\ Min Sun ${ }^{1, *}$ \\ Zhixiao Wangl,* \\ Qi Fu' \\ Mengdei $\mathrm{Cao}^{\prime}$ \\ Zhenxin Zhu' \\ Chuchen Meng' \\ Yan Yan' \\ Jia Mao' \\ Hua Tao' \\ Xiaoping Huang' \\ Zheng Lin ${ }^{2}$ \\ Tao Yang' \\ Wei He' \\ 'Department of Endocrinology, \\ 2Department of Nursing, The First \\ Affiliated Hospital of Nanjing Medical \\ University, Nanjing, People's Republic \\ of China \\ *These authors contributed equally \\ to this work
}

Background: The People's Republic of China has the largest population affected by osteoporosis in the world. However, no population-based survey of osteoporosis awareness in People's Republic of China has been reported. This study investigated the level of basic awareness of osteoporosis in a large community in People's Republic of China. The relationship between level of awareness and quantitative ultrasound (US) measurements at the calcaneus was also assessed.

Methods: A questionnaire was completed by 9983 men and women aged 40 years or older in Nanjing, People's Republic of China, between June and December 2011. During this time, the study participants underwent quantitative US measurement. Data from 9049 of the subjects were included in the final analysis.

Results: The proportion of subjects who were aware of osteoporosis was very low. Only $30.7 \%$ had heard of osteoporosis, and only $18.5 \%$ had heard of osteoporotic fracture. In total, $52.9 \%$ of the subjects drank milk, $16.0 \%$ took calcium, $7.1 \%$ took vitamin $\mathrm{D}$, and $47.2 \%$ were performing regular physical activity. Logistic regression showed that more highly educated older women had significantly better awareness of osteoporosis $(P<0.05)$. Subjects with a history of a previous osteoporotic fracture also had better awareness $(P<0.05)$ than subjects without such a history, except for those who drank milk. Similar to previous reports, female sex, old age, a low education level, and a personal history of osteoporotic fracture were significantly associated with a low quantitative US measurement $(P<0.001)$. Further, drinking milk and having not heard of osteoporosis were significantly associated with a higher quantitative US measurement $(P<0.05)$, while other indicators of osteoporosis awareness were not associated with quantitative US values $(P>0.05)$.

Conclusion: Awareness of osteoporosis in People's Republic of China is very low. National awareness strategies should be implemented, especially for poorly educated young men.

Keywords: osteoporosis, awareness, quantitative ultrasound, Chinese

\section{Introduction}

Osteoporosis is a common disease characterized by low bone mineral density and deterioration in the microarchitecture of bone tissue, leading to an increased risk of fracture. ${ }^{1}$ By 50 years of age, one in three women and one in five men will suffer a fracture in their remaining lifetime. ${ }^{2}$ It is estimated that an osteoporotic fracture occurs every three seconds worldwide. Sustaining any kind of fracture is related to excess mortality in both men and women, and a hip fracture is a powerful independent predictor of long-term excess mortality. ${ }^{3}$ Nowadays, osteoporosis and osteoporotic fractures are becoming important public health problems worldwide, resulting in a heavy economic burden. ${ }^{4}$ For example, patients whose fractures are treated in inpatient facilities may
Correspondence: Wei He

Department of Endocrinology and Metabolism, The First Affiliated Hospital of Nanjing Medical University, 300 Guangzhou Road, 210029 Nanjing, People's Republic of China

Tel +86 I39 5200 I208

Fax +86258378 I78।

Emailxuhan43@I63.com 
subsequently need hospitalization for postoperative complications, such as chest infections, venous thromboembolism, or pneumonia. ${ }^{5}$ With its rapidly aging population, People's Republic of China has the largest number of people affected by osteoporosis in the world, where the disease currently affects more than 6.9 million people over the age of 50 years and causes about 687,000 hip fractures each year. ${ }^{6}$

Due to the devastating effects of osteoporosis, preventive strategies should be implemented to reduce the incidence of osteoporotic fractures in the future. "Three steps to unbreakable bones" is recommended by the International Osteoporosis Foundation, ${ }^{2}$ which describes a combination of staying active, eating a diet rich in calcium, and avoiding vitamin D deficiency to improve bone and muscle health and reduce the risk of osteoporosis. Both calcium and vitamin D are essential components of an integrated strategy for prevention and treatment of osteoporosis in patients with dietary insufficiency. ${ }^{7}$ In order to plan effective interventional projects, it is necessary to determine the current state of awareness about osteoporosis in the Chinese community.

There have already been several studies examining knowledge about osteoporosis in Eastern countries. ${ }^{8-16}$ However, the majority have been surveys based on selected samples which may contain a degree of bias. Further, most of the studies reported have involved relatively small samples of women, and there is little published information about awareness of osteoporosis at the population level. The aim of this large cross-sectional study was to determine the level of basic awareness about osteoporosis in a large Chinese community. The relationship between awareness of osteoporosis in the community and quantitative ultrasound (US) values was also investigated. Quantitative US is a convenient method for estimation of bone mass and provides an index of bone strength, reflecting bone structure as well as bone density. ${ }^{17}$ It is used as a screening tool for low bone density and can predict fragility fractures. ${ }^{18}$

\section{Materials and methods Subjects}

The present cross-sectional study was a part of a populationbased program investigating the epidemiology of metabolic disease. For this survey, a simple self-administered questionnaire was distributed by experienced physicians in 11 adjacent communities in Gulou, a large district of Nanjing, People's Republic of China, between June and December 2011. During the recruiting phase, residents aged 40 years and older were invited by advertisement, telephone, or door-to-door visits to participate. Finally, 10,030 women and men agreed to take part. Because the study focused mainly on awareness of osteoporosis and on quantitative US measurement, subjects who could not communicate normally, failed to complete the questionnaire or gave unclear answers, did not attend for quantitative US measurement, or had non-osteoporotic fracture history but other fractures were excluded.

\section{Materials}

After finishing the investigation for metabolic disease, the subjects were asked if they would be willing to complete an osteoporosis awareness questionnaire, designed by three osteoporosis experts to include demographic characteristics (including sex, age, height, weight, menopausal status in females, educational background, fracture history in detail, ie, age at which the fracture occurred, as well as its anatomical location and cause) and six simple questions concerning basic awareness: $:^{2,6,7}$

- Have you heard of osteoporosis before?

- Have you heard of osteoporotic fractures before?

- Do you drink milk regularly? (such as a cup of fresh milk or yoghurt daily)

- Do you consciously take daily calcium? (such as a daily calcium carbonate supplement)

- Do you consciously take vitamin D? (such as a daily supplement of one or two drops of vitamin D)

- Do you perform regular physical activity (such as daily weight-bearing activities like running, climbing stairs, jumping, or weight-lifting).

The answer to each question was required to be "yes" or "no". In total, $9983(99.5 \%)$ subjects provided written informed consent and completed the awareness questionnaire in this survey. The study was carried out in compliance with the Declaration of Helsinki and was approved by the ethics committee at the First Affiliated Hospital of Nanjing Medical University.

All fractures occurring in subjects older than 25 years were recorded, with an osteoporotic fracture defined as a fracture caused by minor trauma equivalent to that generated by a fall from a standing height or lower. Fractures occurring at the hip, vertebra, femur, lower leg, pelvis, forearm, upper arm, and ribs were deemed to be osteoporotic, whereas fractures of the fingers, face, skull, and toes were not. ${ }^{19,20}$ Fragility fractures were diagnosed by two experts on the basis of self-reporting by subjects and their previous medical records. If the opinions of the two experts differed, the third expert was asked to make the diagnosis.

Baseline quantitative US data were collected as part of the principal investigation for metabolic disease. 
Broadband ultrasound attenuation (BUA) and speed of sound (SOS) were measured at the left calcaneus in each participant using the same Sahara ultrasound machine (Hologic Corporation, Bedford, MA, USA) operated by the same two trained physicians. If a previous fracture was reported at the left calcaneus, BUA and SOS were measured on the right side. The machine was calibrated before each measurement in accordance with the manufacturer's recommendations.

\section{Statistical analysis}

The preliminary data were double-checked. All analyses were performed using Statistical Package for the Social Sciences version 13.0 for Windows software (SPSS Inc, Chicago, IL, USA). Descriptive statistics (means, standard deviations, percentages) were used to describe the characteristics of the participants. The chi-squared test was used to compare the level of awareness of osteoporosis according to sex, menopausal status, age, educational background, and history of osteoporotic fracture. Binary logistic regression was used to analyze the relationship between the above factors and awareness of osteoporosis. One-way analysis of variance was used to determine whether differences in levels of awareness of osteoporosis were correlated with quantitative US values (BUA and SOS) at the calcaneus, and multiple linear regression was used to identify factors influencing quantitative US values. All $P$ values reported are two-tailed and statistical significance was accepted at $P<0.05$.

\section{Results \\ Subject characteristics}

Of the 9983 potential participants, 276 were excluded because of failure to provide clear answers on the questionnaire, and a further 300 were excluded because of lack of quantitative US measurement. Of the remaining 9407, 358 were excluded because of lack of an osteoporotic fracture. Therefore, data from 9049 subjects were available for analysis. Of these, 3058 $(33.8 \%)$ were men, and the female to male ratio was $1.96: 1$. The mean age of the total sample was $58.0 \pm 9.1(40-87)$ years, and the average body mass index was $24.2 \pm 3.9 \mathrm{~kg} / \mathrm{m}^{2}$. In total, $4805(80.2 \%)$ of the female subjects were postmenopausal (mean age $59.9 \pm 7.7$ years), and the mean age of the premenopausal women was $46.6 \pm 4.0$ years. The men were older than the women on average $(59.6 \pm 9.2$ years versus $57.2 \pm 9.8$ years, respectively, $P<0.001)$, and had a higher body mass index $\left(24.5 \pm 3.8\right.$ versus $24.1 \pm 3.9 \mathrm{~kg} / \mathrm{m}^{2}$, $P<0.001)$. An osteoporotic fracture was identified in 803 $(8.9 \%)$ subjects, of whom 617 were women and 186 were men.
Data on the baseline characteristics of the individuals included in this study are shown in Table 1.

\section{Level of basic awareness of osteoporosis}

Only $30.7 \%$ of the subjects had heard of osteoporosis before and only $18.5 \%$ had heard of osteoporotic fractures. In total, $52.9 \%$ of subjects drank milk, $16.0 \%$ took calcium, $7.1 \%$ took vitamin D, and $47.2 \%$ undertook physical activity on a regular basis (Table 1). The proportion of women who had heard of osteoporosis before was significantly higher than in men $(31.9 \%$ versus $28.5 \%$, respectively, $P<0.001)$. Similarly, the proportion of women who drank milk and took calcium and vitamin $\mathrm{D}$ were significantly greater than in men (all $P<0.05)$.

There were no significant differences between the numbers of men or women who had heard of osteoporotic fracture before and those undertaking regular physical activity (each $P>0.05)$. Fewer postmenopausal than premenopausal women had heard of osteoporotic fracture $(17.7 \%$ versus $22.5 \%$, respectively, $P<0.001)$ or drank milk $(52.4 \%$ versus $59.4 \%, P<0.001)$. However, more postmenopausal women than premenopausal women were taking calcium $(20.6 \%$ versus $13.4 \%$, respectively, $P<0.001)$ and vitamin D $(9.3 \%$ versus $5.1 \%, P<0.001)$. The proportion of subjects who had heard of osteoporotic fracture was highest in the youngest age group (20.3\% at age $40-49$ years, $P<0.05)$. Older people were found to have better awareness of osteoporosis but not in terms of having heard of osteoporotic fracture. People with higher education were found to have better awareness of osteoporosis $(P<0.05)$. Subjects with a previous osteoporotic fracture had better awareness than those without such a history $(P<0.05)$, but not for those drinking milk $(P>0.05)$.

In binary logistic regression, female sex, older age, and a higher level of education were associated with better awareness of osteoporosis (Table 2). Given that most people in this study population only learned of osteoporosis after the occurrence of an osteoporotic fracture, subjects with a previous history of osteoporosis fracture had better awareness $(P<0.05)$, except for drinking milk.

\section{Relationship between osteoporosis awareness and quantitative US values}

The mean BUA was $73.68 \pm 16.76 \mathrm{~dB} / \mathrm{MHz}$ and the mean SOS was $1537.33 \pm 30.20 \mathrm{~m} / \mathrm{sec}$ for all subjects included (Table 1). Compared with women, men had both higher BUA and higher SOS $(P<0.001)$. Similarly, premenopausal women had both higher BUA and SOS than postmenopausal women $(P<0.001)$. Consistent with previous studies, 
Table I Basic characteristics of participants and awareness of osteoporosis

\begin{tabular}{|c|c|c|c|c|c|c|c|c|c|}
\hline & n (\%) & $\begin{array}{l}\text { Heard of } \\
\text { osteoporosis } \\
\text { (\%) }\end{array}$ & $\begin{array}{l}\text { Heard of } \\
\text { osteoporotic } \\
\text { fracture (\%) }\end{array}$ & $\begin{array}{l}\text { Drinking } \\
\text { milk (\%) }\end{array}$ & $\begin{array}{l}\text { Taking } \\
\text { calcium } \\
(\%)\end{array}$ & $\begin{array}{l}\text { Taking } \\
\text { vitamin D } \\
(\%)\end{array}$ & $\begin{array}{l}\text { Doing } \\
\text { physical } \\
\text { activity (\%) }\end{array}$ & $\begin{array}{l}\text { BUA } \\
(\mathrm{dB} / \mathrm{MHz}) \\
(\text { mean } \pm \text { SD) }\end{array}$ & $\begin{array}{l}\text { SOS } \\
(\mathrm{m} / \mathrm{sec}) \\
(\text { mean } \pm \text { SD) }\end{array}$ \\
\hline Total & $9049(100)$ & 30.7 & 18.5 & 52.9 & 16.0 & 7.1 & 47.2 & $73.68 \pm 16.76$ & $1537.33 \pm 30.20$ \\
\hline \multicolumn{10}{|l|}{ Sex } \\
\hline Male & 3058 (33.8) & $28.5^{\mathrm{a}}$ & 18.1 & $51.1^{\mathrm{b}}$ & $9.8^{a}$ & $4.6^{\mathrm{a}}$ & 47.5 & $76.39 \pm 15.93^{a}$ & $|540.88 \pm 30.3|^{a}$ \\
\hline Female & 5991 (66.2) & 31.9 & 18.6 & 53.8 & 19.2 & 8.4 & 47.0 & $72.30 \pm 17.00$ & $1535.52 \pm 29.98$ \\
\hline \multicolumn{10}{|c|}{ Postmenopausal } \\
\hline No & $1186(13.1)$ & 33.2 & $22.5^{\mathrm{a}}$ & $59.4^{a}$ & $13.4^{\mathrm{a}}$ & $5.1^{\mathrm{a}}$ & 45.1 & $79.15 \pm|5.4|^{a}$ & $|549.57 \pm 28.2|^{a}$ \\
\hline Yes & $4805(53.1)$ & 31.6 & 17.7 & 52.4 & 20.6 & 9.3 & 47.5 & $70.60 \pm 16.95$ & $1532.05 \pm 29.39$ \\
\hline \multicolumn{10}{|l|}{ Age (years) } \\
\hline $40-49$ & $1885(20.8)$ & $29.6^{\mathrm{b}}$ & $20.3^{b}$ & $52.1^{a}$ & $10.6^{\mathrm{a}}$ & $5.0^{\mathrm{a}}$ & $40.4^{\mathrm{a}}$ & $77.59 \pm 15.13^{a}$ & $1545.34 \pm 27.67^{\mathrm{a}}$ \\
\hline $50-59$ & $3232(35.7)$ & 29.0 & 18.0 & 51.1 & 15.0 & 6.7 & 45.5 & $74.74 \pm 16.42$ & $1539.52 \pm 29.92$ \\
\hline $60-69$ & $2758(30.5)$ & 32.7 & 18.7 & 52.6 & 18.1 & 7.9 & 51.2 & $71.42 \pm 16.97$ & $1532.56 \pm 29.77$ \\
\hline$\geq 70$ & $|17|(12.9)$ & 32.9 & 16.2 & 59.7 & 25.5 & 10.0 & 53.3 & $69.78 \pm 18.00$ & $1529.67 \pm 32.34$ \\
\hline \multicolumn{10}{|c|}{ Educational background } \\
\hline Illiteracy & $403(4.6)$ & $24.3^{\mathrm{a}}$ & $17.6^{\mathrm{b}}$ & $35.2^{\mathrm{a}}$ & $9.7^{\mathrm{a}}$ & $3.5^{\mathrm{a}}$ & $42.4^{\mathrm{a}}$ & $71.27 \pm 17.72^{\mathrm{a}}$ & $1534.09 \pm 30.59^{\mathrm{a}}$ \\
\hline Primacy & $758(8.6)$ & 29.6 & 17.9 & 44.2 & 8.6 & 3.3 & 42.6 & $71.03 \pm 17.63$ & $1532.58 \pm 34.63$ \\
\hline Junior & $2356(26.7)$ & 28.3 & 17.5 & 48.6 & 11.2 & 4.2 & 44.4 & $72.72 \pm 16.89$ & $1535.88 \pm 28.58$ \\
\hline Senior & $3233(36.3)$ & 30.5 & 17.5 & 54.5 & 16.5 & 7.4 & 47.9 & $74.15 \pm 16.41$ & $|538.0| \pm 31.0 \mid$ \\
\hline University & $2076(23.5)$ & 37.4 & 22.6 & 63.8 & 25.7 & 12.8 & 54.4 & $75.41 \pm 16.45$ & $1540.28 \pm 28.65$ \\
\hline \multicolumn{10}{|c|}{ With osteoporotic fracture } \\
\hline Yes & $803(8.9)$ & $43.8^{\mathrm{a}}$ & $21.7^{\mathrm{b}}$ & 55.3 & $36.5^{\mathrm{a}}$ & $17.9^{\mathrm{a}}$ & $61.0^{\mathrm{a}}$ & $68.22 \pm 17.10^{a}$ & $1527.25 \pm 30.24^{\mathrm{a}}$ \\
\hline No & 8246 (9l.I) & 29.5 & 18.2 & 52.6 & 14.0 & 6.1 & 45.8 & $74.21 \pm 16.63$ & $|538.3| \pm 30.12$ \\
\hline
\end{tabular}

Notes: ${ }^{\mathrm{p}} \mathrm{P}<0.001$; ${ }^{\mathrm{b} P}<0.05$.

Abbreviations: BUA, broadband ultrasound attenuation; SOS, speed of sound; SD, standard deviation.

older people had lower BUA and SOS $(P<0.001)$. In addition, individuals with a better educational background had higher BUA and SOS $(P<0.001)$. People with a history of osteoporotic fracture had lower BUA $(68.22 \pm 17.10 \mathrm{~dB} / \mathrm{MHz}$ versus $74.21 \pm 16.63 \mathrm{~dB} / \mathrm{MHz}, P<0.001)$ and lower SOS $(1527.25 \pm 30.24 \mathrm{~m} / \mathrm{sec}$ versus $1538.31 \pm 30.12 \mathrm{~m} / \mathrm{sec}$, $P<0.001)$ than people who did not.

One-way analysis of variance showed that people who drank milk regularly had higher SOS than those who did $\operatorname{not}(1537.91 \pm 30.53 \mathrm{~m} / \mathrm{sec}$ versus $1536.69 \pm 29.81 \mathrm{~m} / \mathrm{sec}$, $P<0.05$, (Table 3). However, no significant difference in BUA was observed between the two groups $(P>0.05)$. Except for those drinking milk, better awareness of osteoporosis was not associated with higher BUA or SOS values. People who had heard of osteoporosis had lower BUA $(72.46 \pm 16.83 \mathrm{~dB} / \mathrm{MHz}$ versus $74.22 \pm 16.10 \mathrm{~dB} / \mathrm{MHz}$, $P<0.001)$ and $\operatorname{SOS}(1534.85 \pm 30.12 \mathrm{~m} / \mathrm{sec}$ versus $1538.43 \pm 30.17 \mathrm{~m} / \mathrm{sec}, P<0.001)$ than those who had not. Further, people taking calcium also had lower BUA (71.90 \pm $17.25 \mathrm{~dB} / \mathrm{MHz}$ versus $74.02 \pm 16.64 \mathrm{~dB} / \mathrm{MHz}, P<0.001)$ and $\operatorname{SOS}(1534.57 \pm 30.00 \mathrm{~m} / \mathrm{sec}$ versus $1537.86 \pm$ $30.21 \mathrm{~m} / \mathrm{sec}, P<0.001$ ), probably because most of these people were taking calcium after a diagnosis of osteoporosis or as a result of having a history of an osteoporotic fracture. The results were similar in people taking vitamin D $(P<0.05)$. People who had heard of osteoporotic fractures had a lower mean SOS $(1536.01 \pm 31.60 \mathrm{~m} / \mathrm{sec}$ versus $1537.63 \pm 29.86 \mathrm{~m} / \mathrm{sec}, P<0.05)$ value than people who had not, but no significant difference in BUA was observed between the groups $(P>0.05)$. Similar results were also observed for those who undertook regular physical activity and those who did not.

In logistic regression analysis, female sex, older age, lower body mass index, and lower educational level were significantly associated with lower BUA $(P<0.001$, Table 4$)$. In addition, people with a history of osteoporotic fracture had lower BUA in multivariate analysis $(P<0.001)$. With regard to awareness of osteoporosis, drinking milk $(P=0.026)$ and not having heard of osteoporosis before were significantly $(P<0.001)$ associated with higher BUA when other variables were adjusted for in multivariate analysis. In logistic regression analysis, female sex, older age, lower educational level, and osteoporotic fracture history were significantly associated with lower SOS $(P<0.001)$. As with BUA, drinking milk $(P=0.007)$ and not having heard of osteoporosis $(P<0.001)$ were significantly associated with higher SOS. Other indicators of awareness of osteoporosis were not associated with $\operatorname{SOS}(P>0.05)$. 


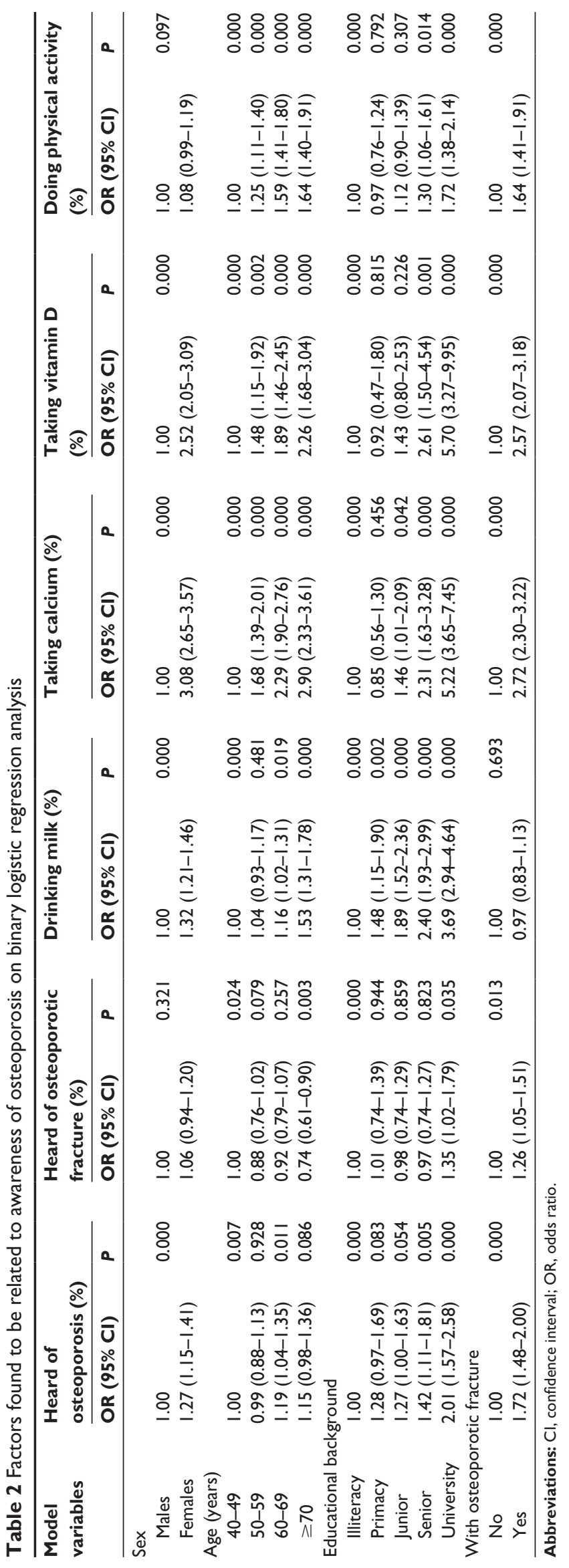

Table 3 Quantitative ultrasound parameters in groups with different awareness

\begin{tabular}{lll}
\hline & BUA (dB/MHz) & SOS (m/sec) \\
\hline $\begin{array}{l}\text { Heard of osteoporosis } \\
\text { Yes }\end{array}$ & $72.46 \pm 16.83^{\mathrm{a}, \mathrm{a}^{\prime}}$ & $1534.85 \pm 30.12^{\mathrm{a}, \mathrm{a}^{\prime}}$ \\
No & $74.22 \pm 16.10$ & $1538.43 \pm 30.17$ \\
Heard of osteoporotic fracture & & \\
$\quad$ Yes & $73.48 \pm 16.85$ & $1536.01 \pm 31.60^{\mathrm{b}, \mathrm{b}^{\prime}}$ \\
No & $73.72 \pm 16.74$ & $1537.63 \pm 29.86$ \\
Drinking milk & & \\
Yes & $73.91 \pm 16.70$ & $1537.91 \pm 30.53^{\mathrm{b}^{\prime}}$ \\
No & $73.42 \pm 16.82$ & $1536.69 \pm 29.8 \mathrm{I}$ \\
Taking calcium & & \\
Yes & $71.90 \pm 17.25^{\mathrm{a}}$ & $1534.57 \pm 30.00^{\mathrm{a}}$ \\
No & $74.02 \pm 16.64$ & $1537.86 \pm 30.21$ \\
Taking vitamin D & & \\
Yes & $71.57 \pm 17.46^{\mathrm{b}}$ & $1534.85 \pm 29.79^{\mathrm{b}}$ \\
No & $73.84 \pm 16.69$ & $1537.52 \pm 30.22$ \\
Doing physical activity & & \\
$\quad$ Yes & $73.38 \pm 16.6 \mathrm{I}$ & $1536.61 \pm 30.16^{\mathrm{b}}$ \\
No & $73.94 \pm 16.89$ & $1537.97 \pm 30.22$ \\
\hline
\end{tabular}

Notes: ${ }^{\mathrm{P}} P<0.001$; ${ }^{\mathrm{b} P}<0.05$; ${ }^{\mathrm{a}} P<0.001$; ${ }^{\mathrm{b}} \mathrm{P}<0.05$ in model adjusted for sex, age, body mass index, educational background, and a history of osteoporotic fracture. Abbreviations: BUA, broadband ultrasound attenuation; SOS, speed of sound.

\section{Discussion}

Campaigns to increase awareness of osteoporosis at national levels were launched in developed Western countries more than a decade ago. ${ }^{21,22}$ To our knowledge, there has not been any population-based interventional approach in People's Republic of China to enhance public awareness of this common disease. One of the first steps in raising awareness is to examine how much is known about the disease amongst the public. ${ }^{23}$ This study assessed the level of awareness of osteoporosis in a Chinese community of people aged 40 years and older. In addition, we determined the relationship between awareness of osteoporosis and quantitative US parameters. Our results suggest that awareness of osteoporosis was very low in our study population. In addition, drinking milk and not having heard of osteoporosis were significantly associated with higher BUA and SOS. Other indicators of awareness of osteoporosis were not associated with BUA and SOS measurements.

At the community level, it is generally accepted that it is normal to lose height with aging. Osteoporosis is a "silent disease" and is not widely recognized in the community, which would account for why only $30.7 \%$ of our study population had heard of osteoporosis. This proportion was $87.1 \%$ in a Malaysian population attending health-related forums, ${ }^{8}$ $58 \%$ in Singaporean women living in the community, ${ }^{9}$ and $60.8 \%$ in women attending primary care centers in Turkey. ${ }^{10}$ 
Table 4 Factors found to be related to quantitative ultrasound based on multivariate linear regression analysis

\begin{tabular}{|c|c|c|c|c|c|c|c|c|}
\hline \multirow[t]{2}{*}{ Model variables } & \multicolumn{4}{|l|}{ BUA } & \multicolumn{4}{|l|}{ sos } \\
\hline & B & Beta & $\boldsymbol{t}$ & $\boldsymbol{P}$ & B & Beta & $t$ & $\boldsymbol{P}$ \\
\hline Sex (women versus men) & -4.119 & -0.116 & -10.643 & 0.000 & -5.863 & -0.092 & -8.407 & 0.000 \\
\hline Age (older versus younger) & -0.312 & -0.169 & -15.558 & 0.000 & -0.636 & -0.191 & -17.613 & 0.000 \\
\hline Body mass index (higher versus lower) & 0.194 & 0.037 & 3.530 & 0.000 & 0.159 & 0.017 & 1.604 & 0.109 \\
\hline Education background (higher versus lower) & 0.770 & 0.049 & 4.437 & 0.000 & 1.120 & 0.040 & 3.583 & 0.000 \\
\hline With osteoporotic fracture history & -4.027 & -0.069 & -6.421 & 0.000 & -7.583 & -0.072 & $-6.7 \mid 4$ & 0.000 \\
\hline Heard of osteoporosis before & -2.347 & -0.065 & -4.392 & 0.000 & -3.816 & -0.058 & -3.965 & 0.000 \\
\hline Heard of osteoporotic fractures & 1.142 & 0.027 & 1.857 & 0.063 & 0.532 & 0.007 & 0.480 & 0.631 \\
\hline Drinking milk daily & 0.795 & 0.024 & 2.227 & 0.026 & 1.740 & 0.029 & 2.705 & 0.007 \\
\hline Taking calcium daily & 0.162 & 0.004 & 0.278 & 0.781 & 0.168 & 0.002 & 0.160 & 0.873 \\
\hline Taking vitamin $D$ daily & -0.675 & -0.010 & -0.846 & 0.398 & 0.403 & 0.003 & $0.28 \mathrm{I}$ & 0.779 \\
\hline Doing physical activity daily & 0.625 & 0.019 & 1.574 & 0.116 & 1.018 & 0.017 & 1.423 & 0.155 \\
\hline
\end{tabular}

Notes: bold figures indicate statistical significance between awareness and quantitative ultrasound.

Abbreviations: BUA, broadband ultrasound attenuation; SOS, speed of sound.

A recent study reported that $77 \%$ of male patients aged $21-73$ years had heard of osteoporosis at Saint Joseph Hospital in Chicago, ${ }^{11}$ and that $96 \%$ of Greek women being treated for osteoporosis or osteopenia had heard of osteoporosis. ${ }^{12}$ However, subject selection, age range, sex, and menopausal status of a sample may influence the degree of awareness in a study population.

Osteoporosis is generally accepted as a "women's health issue", and is particularly prevalent among postmenopausal women. As estrogen levels fall, the risk of osteoporosis increases. ${ }^{21}$ Lower bone mineral density and an increased fracture risk were found in more women than men and in more postmenopausal women than premenopausal women in our survey. Because of their lower bone density and higher rate of fractures, postmenopausal women suffered from complications of osteoporosis, which strengthen their awareness of the disease. Similar results have been reported by other researchers. ${ }^{13}$ Also consistent with previous reports, ${ }^{14-16}$ a higher education level was associated with a greater likelihood of knowing about osteoporosis. Better educated people have more access to information about osteoporosis. Previous studies ${ }^{14-16}$ have suggested that younger people have better awareness of osteoporosis, but the reverse situation was observed in our study. Older people were more likely to suffer from osteoporosis and to have had an osteoporotic fracture, and so may pay close attention to osteoporosis after onset of the disease. In addition, old people have more time to become familiar with the disease upon retirement.

Osteoporosis has frequently been called a "silent disease", given that it is asymptomatic until a fracture occurs, ${ }^{24}$ which explains why subjects with a history of osteoporotic fracture were more likely to know about osteoporosis than those without such a history. In spite of the large number of people in People's Republic of China with osteoporosis, the disease has not been recognized as a major health problem. ${ }^{6}$ People may visit a physician and other health care personnel only when they suffer from low bone mass, bone pain, functional limitation, or fractures caused by the disease. Only then will sufferers learn of osteoporosis and take steps to address the disease.

Consistent with previous studies, older women with a low body mass index had low BUA and SOS. Better educated subjects also had higher BUA and SOS, because of their increased awareness and greater likelihood of taking preventive measures against osteoporosis, which may have led to better bone quality. Interestingly, drinking milk was associated with higher BUA and SOS in this study; in contrast, subjects having heard of osteoporosis had lower BUA and SOS. The probable reason for this is that most subjects in this survey may not have known about osteoporosis until they suffered from low bone mass, bone pain, functional limitation, or bone fragility fractures. It is also likely that with improvement in living standards, an increasing number of people are drinking milk daily, but may not necessarily be aware of the relationship between drinking milk and bone health. Lactose intolerance is relatively common in Chinese and Asian populations, ${ }^{25}$ which may be a reason for people not to drink milk. There is no oral pharmaceutical preparation of vitamin $\mathrm{D}$ available in Mainland People's Republic of China, ${ }^{6}$ which may account for the low intake of vitamin D seen in our study, even though the Institute of Medicine now recommends tripling the daily intake for children and adults to $600 \mathrm{IU}$ per day from $200 \mathrm{IU} /$ day. ${ }^{26} \mathrm{In}$ People's Republic of China, the recommended daily calcium intake for adults is $800 \mathrm{mg} .{ }^{6}$ Given the low rate of awareness about osteoporosis, national osteoporosis awareness strategies are urgently needed. 
The results of our survey may help us to target at-risk individuals and design appropriate health education strategies. First, subjects at high risk should be included in awareness intervention programs. For example, most people with a fracture history in this study were still unaware of osteoporosis. A previous study ${ }^{27}$ also concluded that osteoporosis was rarely recognized by patients with newly diagnosed lowimpact fractures, and the majority of the patients were not managed according to guidelines. Second, according to our findings, males, premenopausal women, young individuals, and those with limited education appear to be less aware of osteoporosis, so should also be targeted. Further, although only $20 \%-25 \%$ of osteoporotic fractures occur in men, ${ }^{28}$ the mortality after hip fracture in men older than 75 years has been reported to be significantly higher than that in women, ${ }^{29}$ emphasizing the importance of interventional education for men.

Provision of knowledge about osteoporosis by physicians could reduce the risk of the disease and future fractures. ${ }^{30}$ It has been recommended that osteoporosis prevention be started at a young age in both women and men. Basically, we should explain to our population clearly what osteoporosis is, its complications, and the major risk factors for this condition. Prevention of osteoporosis and osteoporotic fractures is another important issue. In the management of chronic disease, increased knowledge about the disease is associated with improved patient compliance with its treatment. ${ }^{31}$ Considering the alarmingly low rate of osteoporosis awareness in the Chinese population, it is timely to launch a national osteoporosis awareness campaign like the one implemented in the United States. ${ }^{22}$

Our survey has several limitations. First, People's Republic of China is a developing country with imbalanced economic status. Although the sample size was large, our data came from only one region and are not necessarily representative of People's Republic of China as a whole. Second, the daily milk, calcium, and vitamin D intake was not clear, and the type, frequency, and duration of physical activity undertaken were not explored. Third, quantitative US is not the "gold standard" for diagnosis of osteoporosis. However, BUA and SOS at the calcaneus do provide basic information about bone strength, reflecting both bone structure and bone density. ${ }^{17}$ Osteoporosis or osteopenia is not defined according to the results of quantitative US. ${ }^{32}$ Only the relationship between awareness and quantitative US parameters was assessed in this study.

In conclusion, our present findings suggest that knowledge about osteoporosis in the Chinese population is very low. National osteoporosis awareness strategies should be implemented, especially for poorly educated young men.

\section{Acknowledgment}

This work was supported in part by the Six Kinds of Outstanding Talent Foundation of Jiangsu Province (2010-WS079), the Priority Academic Program Development of Jiangsu Higher Education Institutions, and the National Clinical Key Specialty Construction Projects of China. We thank all the participants in this study, along with Professor Rongbin Yu from Nanjing Medical University for assistance with the statistical analysis.

\section{Disclosure}

The authors report no conflicts of interest in this work.

\section{References}

1. Dempster DW. Osteoporosis and the burden of osteoporosis-related fractures. Am J Manag Care. 2011;17(6):S164-S169.

2. International Osteoporosis Foundation: Three steps to unbreakable bones. Available from: http://www.iofbonehealth.org/bonehealth/threesteps-unbreakable-bones-world-osteoporosis-day. Accessed October 13, 2011.

3. Piirtola M, Vahlberg T, Löppönen M, Räihä I, Isoaho R, Kivelä SL. Fractures as predictors of excess mortality in the aged - a populationbased study with a 12-year follow-up. Eur J Epidemiol. 2008;23(11): 747-755.

4. Pike C, Birnbaum HG, Schiller M, Swallow E, Burge RT, Edgell ET Economic burden of privately insured non-vertebral fracture patients with osteoporosis over a 2-year period in the US. Osteoporos Int. 2011;22(1):47-56.

5. Roche JJ, Wenn RT, Sahota O, Moran CG. Effect of comorbidities and postoperative complications on mortality after hip fracture in elderly people: prospective observational cohort study. BMJ. 2005;331(7529): 1374.

6. Chinese Health Promotion Society. Summary statement of osteoporosis white paper China 2008. Chin J Health Manag. 2009;3(3):148-154. Chinese.

7. Boonen S, Rizzoli R, Meunier PJ, et al. The need for clinical guidance in the use of calcium and vitamin D in the management of osteoporosis: a consensus report. Osteoporos Int. 2004;15(7):511-519.

8. Yeap SS, Goh EM, Das Gupta E. Knowledge about osteoporosis in a Malaysian population. Asia Pac J Public Health. 2010;22(2): 233-241.

9. Saw SM, Hong CY, Lee J, et al. Awareness and health beliefs of women towards osteoporosis. Osteoporos Int. 2003;14(7):595-601.

10. Gemalmaz A, Oge A. Knowledge and awareness about osteoporosis and its related factors among rural Turkish women. Clin Rheumatol. 2008;27(6):723-728.

11. Shawa H, Favela E, Diaz J. Knowledge of osteoporosis among men in the primary care setting. South Med J. 2011;104(8):584-588.

12. Alexandraki KI, Syriou V, Ziakas PD, et al. The knowledge of osteoporosis risk factors in a Greek female population. Maturitas. 2008;59(1):38-45.

13. Juby AG, Davis P. A prospective evaluation of the awareness, knowledge, risk factors and current treatment of osteoporosis in a cohort of elderly subjects. Osteoporos Int. 2001;12(8):617-622.

14. Drozdzowska B, Pluskiewicz W, Skiba M. Knowledge about osteoporosis in a cohort of Polish females: the influence of age, level of education and personal experiences. Osteoporos Int. 2004;15(8):645-648. 
15. Vytrisalova M, Kubena A, Vlcek J, Palicka V, Hala T, Pavelka K. Knowledge of osteoporosis correlated with hormone therapy use and health status. Maturitas. 2007;56(1):21-29.

16. Kutsal YG, Atalay A, Arslan S, et al. Awareness of osteoporotic patients. Osteoporos Int. 2005;16(2):128-133.

17. Glüer CC. Quantitative ultrasound techniques for the assessment of osteoporosis: expert agreement on current status. J Bone Miner Res. 1997;12(8):1280-1288.

18. Liu JM, Ma LY, Bi YF, et al. A population-based study examining calcaneus quantitative ultrasound and its optimal cut-points to discriminate osteoporotic fractures among 9352 Chinese women and men. J Clin Endocrinol Metab. 2012;97(3):800-809.

19. Pike CT, Birnbam HG, Schiller M, Swallow E, Burge RT, Edgell ET. Prevalence and costs of osteoporotic patients with subsequent non-vertebral fractures in the US. Osteoporos Int. 2011;22(10): 2611-2621.

20. Ross PD. Clinical consequences of vertebral fractures. Am J Med. 1997;103(2A):30S-42S.

21. Edwards L, Fraser M. How do we increase awareness of osteoporosis? Baillieres Clin Rheumatol. 1997;11(3):631-644.

22. Foundation for Osteoporosis Research and Education. The national osteoporosis awareness plan. Available from: http://www.fore.org/pdf/ AOA_REPORT.pdf. Accessed May 24, 2004.

23. Werner P. Knowledge about osteoporosis: assessment, correlates and outcomes. Osteoporos Int. 2005;16(2):115-127.

24. Hamdy RC. Osteoporosis, the deafening silent epidemic. South Med J. 2002;95(6):567-568.
25. Jackson KA, Savaiano DA. Lactose maldigestion, calcium intake and osteoporosis in African-, Asian-, and Hispanic-Americans. J Am Coll Nutr. 2001;20(2):198S-207S.

26. Institute of Medicine Committee to Review Dietary Reference Intakes for Vitamin D and Calcium; Ross AC, Taylor CL, Yaktine AL, Del Valle HB, editors. Dietary reference intakes for calcium and vitamin D. Washington, DC: National Academies Press; 2011. Available from: http:/www.ncbi.nlm.nih.gov/pubmed/21796828. Accessed May 24, 2013.

27. Castel H, Bonneh DY, Sherf M, Liel Y. Awareness of osteoporosis and compliance with management guide-lines in patients with newly diagnosed low-impact fractures. Osteoporos Int. 2001;12(7):559-564.

28. Szulc P, Garnero P, Munoz F, Marchand F, Delmas PD. Cross-sectional evaluation of bone metabolism in men. J Bone Miner Res. 2001;16(9): $1642-1650$.

29. Haney EM, Bliziotes MM. Male osteoporosis: new insights in an understudied disease. Curr Opin Rheumatol. 2008;20(4):423-428.

30. Sedlak CA, Doheny MO, Jones SL. Osteoporosis prevention in young women. Orthop Nurs. 1998;17(3):53-60.

31. Kennedy AP, Rogers AE. Improving patient involvement in chronic disease management: the views of patients, GPs and specialists on a guidebook for ulcerative colitis. Patient Educ Couns. 2002;47(3): 257-263.

32. Kanis JA, Melton LJ 3rd, Christiansen C, Johnston CC, Khaltaev N. The diagnosis of osteoporosis. J Bone Miner Res. 1994;9(8): 1137-1141.
Clinical Interventions in Aging

\section{Publish your work in this journal}

Clinical Interventions in Aging is an international, peer-reviewed journal focusing on evidence-based reports on the value or lack thereof of treatments intended to prevent or delay the onset of maladaptive correlates of aging in human beings. This journal is indexed on PubMed Central, MedLine, the American Chemical Society's 'Chemical Abstracts

\section{Dovepress}

Service' (CAS), Scopus and the Elsevier Bibliographic databases. The manuscript management system is completely online and includes a very quick and fair peer-review system, which is all easy to use. Visit http://www.dovepress.com/testimonials.php to read real quotes from published authors. 